\title{
POESIA INFANTIL: O RELATO DE UMA BELA EXPERIÊNCIA
}

\author{
CHILD POETRY: THE REPORT OF A BEAUTIFUL EXPERIENCE
}

CRISTIANE LUMERTZ KLEIN DOMINGUES

FACULDADE INEDI - CESUCA

\begin{abstract}
RESUMO: $\mathrm{O}$ trabalho tem por finalidade descrever um projeto realizado numa comunidade carente de Porto Alegre, com um grupo de crianças entre 7 e 14 anos. A investigação aconteceu no $2^{\circ}$ semestre do ano de 2016, numa pesquisa de campo, que teve por base teórica o livro de Maria Alberta Menéres O poeta fazse aos 10 anos. Os encontros aconteciam em forma de oficinas por meio do contato com o gênero poético, com o objetivo de despertar no indivíduo o gosto pelo poema através do desenvolvimento da imaginação, porque se desejava comprovar que o contato da criança com o gênero poético pode aprimorar a leitura, incentivar a escrita e melhorar a oralidade. As obras utilizadas nas oficinas foram as de Mário Quintana: Pé de pilão, Lili inventa o mundo, Sapato furado, Sapo amarelo, O batalhão das letras e Nariz de vidro. Durante quatro meses as crianças tiveram contato semanal com o gênero poético nas oficinas, e eram convidadas a produzirem seus próprios poemas. $O$ trabalho na oficina acontecia em três etapas: leitura do poema, conversa sobre o poema, e uma proposta de escrita; denominadas, respectivamente de: $\mathrm{O}$ poema, Compreendendo, Agora vou escrever!
\end{abstract}

Palavras-chave: Poema Infantil; Oficina; Leitura e Escrita

\begin{abstract}
The purpose of this paper is to describe a project carried out in a poor community of Porto Alegre, with a group of children between 7 and 14 years old. The investigation took place in the 2 nd semester of 2016, in a field research, which was based on the book by Maria Alberta Menéres. The poet is at 10 years old. The meetings took place in the form of workshops through contact with the poetic genre, with the aim of arousing in the individual a taste for the poem through the development of imagination, because it was desired to prove that the child's contact with the poetic genre can improve reading. , encourage writing and improve orality. The works used in the workshops were those of Mario Quintana: Pestle, Lili Invents the World, Flat Shoes, Yellow Frog, The Battalion of Letters and Glass Nose. For four months the children had weekly contact with the poetic genre in the workshops, and were invited to produce their own poems. Work in the workshop took place in three stages: reading the poem, talking about the poem, and a writing proposal; respectively called: The Poem, Understanding, Now I will write!
\end{abstract}

Keywords: Children's Poem; Workshop; Reading and writing 


\section{INTRODUÇÃO}

O trabalho que será descrito foi realizado através de oficinas, sendo oficina entendida, segundo Vieira e Volquind (1996), como um local em que o trabalho é realizado de forma que seja elaborada uma produção pelo participante e, portanto, é uma modalidade que visa à ação. O espaço tem que contar com vivências, reflexão e construção do saber. É um lugar para aprender fazendo, sendo importante levar o aluno a pensar, sentir, experimentar, investigar, discutir e problematizar. A relação monitor-participante numa oficina funciona como numa equipe de trabalho, em que cada um contribui com sua experiência. O professor é quem coordena, mas a ele é permitido também aprender.

As oficinas aconteceram para despertar no indivíduo o gosto pelo poema através do desenvolvimento da imaginação, demonstrando que o contato da criança com o gênero poético aprimora a leitura, incentiva a escrita e melhora a oralidade. As 15 crianças que frequentaram o projeto viviam numa comunidade carente de Porto Alegre. Durante quatro meses as crianças tiveram contato semanal com o gênero poético nas oficinas, e eram convidadas a produzirem seus próprios poemas. As primeiras produções foram mais dificéis, necessitando de ajuda a todo momento, à medida que foram acontecendo as oficinas, as crianças começaram a ficar mais soltas e confiantes na sua capacidade criadora, e a produzirem os poemas com mais facilidade e de forma prazerosa.

Isso não significa que apenas essa experiência seja o remédio para todos os problemas de escrita e leitura na escola, porque sabe-se que o caminho das dificuldades apresentadas pelos estudantes começa bem cedo, vem desde a alfabetização, e se propaga por toda vida estudantil da criança e do jovem, gerando a incapacidade de inserção na sociedade devido a carência de competências. É o circuito da pobreza cultural, mais visível na comunidade menos privilegiada, por isso, sua solução exige continuidade e muita dedicação da escola, não somente com projetos isolados, mas com uma prática efetiva com os gêneros textuais na sala de aula.

Assim, tentando romper com a incapacidade de inserção na sociedade pela carência de competências, surge esse trabalho, que deseja colocar o jovem carente na sociedade através do contato com o gênero poético, para que a criança adquira melhores habilidades com a leitura e

com a escrita. É especialmente essa inserção pela poesia que vai proporcionar a capacidade de 
emocionar, que significa o direito de sentir, ver o belo, apontando um caminho para o desenvolvimento integral do indivíduo. Segundo os Parâmetros Curriculares Nacionais:

Um leitor competente só pode constituir-se mediante uma prática constante de leitura de textos de fato, a partir de um trabalho que deve se organizar em torno da diversidade de textos que circulam socialmente. Esse trabalho pode envolver todos os alunos, inclusive aqueles que ainda não sabem ler convencionalmente. (BRASIL, 2001, p.54)

A investigação aconteceu no $2^{\circ}$ semestre do ano de 2016, numa pesquisa de campo, que teve por base o livro de Maria Alberta Menéres O poeta faz-se aos 10 anos, que pretendia despertar no indivíduo o gosto pelo poema através do desenvolvimento da imaginação, por meio das sugestões de trabalho da autora. Maria Alberta Menéres utiliza na sua proposta uma motivação do assunto, conversa sobre ele com os alunos e no final da aula eles produzem um poema. A pesquisadora utilizou a mesma ordem nas oficinas, somente alterando a motivação porque usou para isso os poemas de Mário Quintana. Os poemas de Mário Quintana foram escolhidos por instigarem o imaginário, quando o poeta privilegia imagens e temas diversificados de interesse da infância. As obras utilizadas nas oficinas foram as de Mário Quintana: Pé de pilão, Lili inventa o mundo, Sapato furado, Sapo amarelo, O batalhão das letras e Nariz de vidro.

A pesquisa aqui proposta foi analisada qualitativamente, o que demandou uma ampla observação do contexto, contudo, sem juízo de valor, a fim comprovar ou não, as hipóteses enunciadas. Ainda de acordo com Marconi e Lakatos: "Uma fonte rica para a construção de hipóteses é a observação que se realiza dos fatos ou da correlação existente entre eles. As hipóteses terão a função de comprovar essas relações e explicá-las" (MARCONI, LAKATOS, 2009, p.132). A pesquisa de campo, segundo Markoni e Lakatos,

[...]tem a finalidade de desenvolver hipóteses, aumentar a familiaridade do pesquisador com um ambiente, fato ou fenômeno, para a realização de uma pesquisa futura mais precisa ou modificar e clarificar conceitos. Empregam-se geralmente procedimentos sistemáticos ou para a obtenção de observações empíricas ou para as análises de dados (ou ambas, simultaneamente). Obtém-se frequentemente descrições tanto quantitativas quanto qualitativas do objeto de estudo, e o investigador deve conceituar as interrelações entre as propriedades do fenômeno, fato ou ambiente observado (MARCONI, LAKATOS, 2009, p.188).

O trabalho nas oficinas contou com a participação de 15 crianças, de um bairro carente em Porto Alegre, que participavam no contra turno de aula em um projeto de leitura, promovido por um grupo de pesquisa, de uma faculdade privada de Porto Alegre. 
Os dados foram coletados por meio de observações nas oficinas, escritas com detalhes em um diário, também com os trabalhos realizados pelas crianças. A autoria das produções escritas das crianças será indicada por meio de letras, a fim de garantir o sigilo da pesquisa. A análise dos dados contou com a investigação dos registros e das atividades feitas pelas crianças durante as oficinas.

\section{O CONTATO COM O GÊNERO POÉTICO}

O trabalho na oficina acontecia em três etapas: leitura do poema, conversa sobre o poema, e uma proposta de escrita; denominadas, respectivamente de: O POEMA, COMPREENDENDO, AGORA VOU ESCREVER! Antes da leitura do poema havia uma proposta de motivação, que contava sempre com atividades diversificadas e interessantes referentes à temática do poema a ser trabalhado, com o objetivo de mobilizar o desejo de ler do grupo. As atividades de motivação envolveram álbum de fotografias, contorno do corpo de um colega sobre papel pardo, pintura com tinta, dobraduras, música, fita de vídeo, construção de brinquedos com material reciclável, recorte e colagem, pintura e pesquisa sobre a biografia de Monet. O trabalho em equipe era bastante valorizado nesse momento, para a confrontação de idéias, incentivando a cooperação e a leitura.

Foram selecionados quinze poemas de Mário Quintana dos livros já mencionados, em conformidade com as sugestões de atividades de Maria Alberta Menéres. Sendo utilizados dois livros integralmente Pé de Pilão (1999) e O batalhão das letras (1999), e treze poemas das demais obras do poeta, na seguinte ordem: "Azrafel” (2006), "Conto de todas as cores” (2005), "Velha história” (2005), "Recordo ainda" (2003), “O poema” (2006), "Noturno” (2006) "Ponte do riacho" (2006), "De um diário íntimo do fim do Século trinta" (2006), “Os hóspedes" (1999), "Se eu fosse um padre” (2003), "Poema” (2003), "Canção do primeiro do ano" (2005), "Poema do fim do ano" (2005).

Depois de ler o poema com o grupo, as crianças trocavam idéias sobre os versos, como incentivo ao desenvolvimento da oralidade; o vocabulário também era discutido. Todos os passos realizados levavam à escrita, por isso eram feitas várias atividades com o poema lido, a fim de facilitar o aparecimento de ideias no final. As atividades encaminhavam para a escrita de um poema no final. A seguir, são apresentadas as atividades e os versos que sugeriam as produções escritas e alguns poemas criados nas oficinas. 
Foi lido todo o livro Pé de pilão, mas os versos a seguir foram mais salientados: "O pato ganhou um sapato,/ foi logo tirar retrato.// O macaco retratista./ Era mesmo um grande artista" (QUINTANA, 1999, p. 3). Depois de ler os versos, as crianças desenharam sua imagem numa moldura decorada por elas, brincaram de fotógrafo e escreveram um poema sobre infância. E o resultado dessa proposta foi:

\author{
Artista \\ Ser criança \\ É ser artista \\ Porque no tempo da escola é pessimista \\ Mas no sonho é tudo bonito \\ Como num retrato
}

(Criança $\left.\mathrm{E}^{1}\right)$

A seguir, alguns versos do poema "Azrafel": "E vai daí o Anjo dos/ últimos Desejos, que, como todos/ sabem, atende pelo nome de Azrafel,/ compadeceu-se muito e imediatamente/ satisfez as curiosidades do pobre homem,/ transformando-o num fantasma dentro/ de um disco voador" (QUINTANA, 2006, p.4). Essa parte do poema de Quintana mostra uma transformação, o que motivou um trabalho de criação de uma personagem em papel pardo, feita pelo grupo. A personagem criada ganhou um nome (Pé Pequeno), uma identidade e serviu como motivo para escrita:

$$
\begin{aligned}
& \mathrm{P} \text { ato é preto } \\
& \text { E ngoliu o sapato }
\end{aligned}
$$

\footnotetext{
${ }^{1}$ Foram muitos os poemas escritos pelos alunos, mas para fim de organizar o trabalho foi preciso escolher alguns para comporem o diário das oficinas. A escolha dos analisados ocorreu aleatoriamente, sem critério de seleção nenhum.
} 


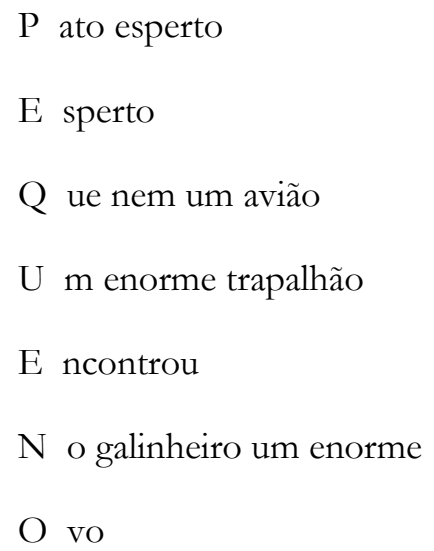

(Criança B)

O poema "Conto de todas as cores" fala da contemplação de algo diferente e inventado: "Eu já escrevi um conto azul, vários até.// Mas este agora é um conto de todas as cores" (QUINTANA, 2005, p. 12). Como exercício de apreender a ver a beleza em todas as coisas, as crianças ficaram sentadas na rua contemplando o dia, e depois elas escreveram:

O dia

O dia de hoje está ensolarado

Ensolarado só no poente

Poente só quando o sol

Está doente.

(Criança F)

Em continuação, foi lido o poema "Velha história": "Era uma vez um homem que estava pescando, Maria. Até que/ apanhou um peixinho! Mas o peixinho era tão pequenininho/ e inocente, e tinha um azulado tão indescritível nas escamas, que/ o homem ficou com pena" (QUINTANA, 2005, p.20). Apreciando a natureza, em especial os peixes, foram feitas dobraduras de peixe e um aquário foi montado. Depois de contar o número de peixes do aquário, eles escreveram seus poemas: 


\author{
1 peixe no mar \\ 2 vão ao bar \\ E 3 não vão a nenhum lugar \\ 4 juntos vão pescar \\ Pra 5 não vão ficar \\ 6 não no mar, porque \\ Com 7 não vou morar.
}

\title{
(Criança T)
}

O livro O batalhão das letras foi trabalhado na íntegra, mas alguns versos foram mais salientados: "E todas as vinte e seis letras que aprendeste num segundo são vinte e seis estrelinhas brilhando no céu do mundo" (QUINTANA, 1999, p.6). Comparando o alfabeto com estrelas, foi feito em conjunto com papel colorido, um céu estrelado, usando recorte e colagem. Uma conclusão foi importante para o grupo, que percebeu o quanto as letras registram coisas bonitas. A proposta de escrita do poema aconteceu de forma coletiva, quando cada um escrevia um verso, usando como motivo o alfabeto:

Rodrigo e as letras

Às vezes penso no alfabeto.

Bem pouco eu penso.

Com a caneta escrevo

Dedo duro,

E não dedo mole.

Fiz um curativo no dedo mole, aguentei a dor.

Hoje a dor passou,

I daí voltou.

Já podia estar curado.

Livre daquela dor.

AManheci sem nenhuma dor, 
Nunca vi dor igual.

O que vou fazer sem dor?

Primeiro vou caminhar,

Quem sabe até correr.

Rodrigo correu até cansar

Saindo do parque quando o tênis estourou.

Tarde ficou!

Um amigo urso encontrou

-Vamos a minha casa amigo urso?

$-\mathbf{X}$, não posso.

-Zenaide minha mãe não deixa.

(Texto Coletivo)

A leitura do poema "Recordo ainda..." motivou falar de criança e brincadeiras infa, comntiso um bilboquê, construído com material reciclável: "Recordo ainda... E nada mais me importa.../ Aqueles dias de uma luz tão mansa./ Que me deixavam, sempre, de lembrança./ Algum brinquedo novo à minha porta" (QUINTANA, 2003, p.43), os versos fizeram surgir um poema no formato do brinquedo:

Brincadeira de criança

A criança gosta de brincar com

Com seu brinquedo favorito

Favoritos de A até o Z

Com A escrevo avião

B escrevo bola

C escrevo

carrinho

D escrevo 


\author{
dado \\ E escrevo \\ encaixe \\ F escrevo \\ ferrorama \\ G escrevo \\ gaita \\ H escrevo \\ helicóptero \\ E a brincadeira \\ Vai até o Z. \\ (Criança C)
}

Ao ler "O poema": "Uma/ formiguinha/ atravessa,/ em diagonal,/ a página ainda/ em branco.// Mas ele,/ aquela noite,/ não escreveu/ nada. Por quê? / Se por ali/ já havia passado/ o frêmito e/ o mistério da vida..." (QUINTANA, 2006, p28), as crianças viram num papel branco a possibilidade de criar, primeiro artisticamente, usando diversos materiais e depois escrevendo:

Papel branco

Aquele era um papel branco

Branco como borracha.

Borracha bem branquinha.

Branquinha que nem o papel

Papel branquinho é sem graça.

Graça quando nele escrevemos 
Escrevemos com o lápis

Lápis coisas engraçadas escreve.

Escreve o que é alegre e triste.

Triste não quero escrever.

Escrever para mim é sempre alegria.

(Criança)

Depois de olhar o livro 111 poemas para crianças, do Sérgio Capparelli, na parte de poemas visuais, as crianças entenderam o que é um ideograma e formaram um com recortes de revista. Todos leram os seguintes versos do poema "Noturno": "Desconfio muito que nos dias de nevoeiro os fantasmas aproveitem para passear incógnitos pelas ruas" (QUINTANA, 2006, p.15). Eles substituíram a palavra fantasma por outra personagem. E com a personagem escreveram um poema no formato da figura escolhida.

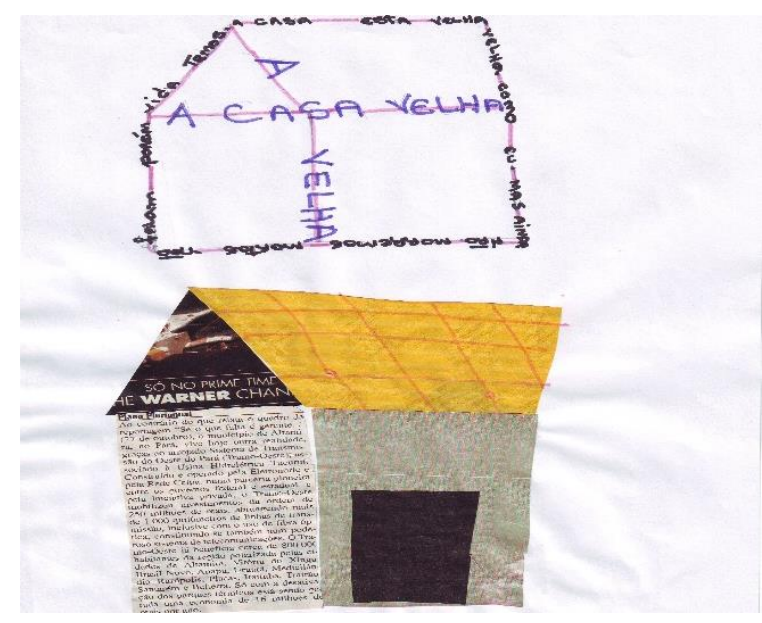

Fonte: trabalho do aluno registrado no diário

Partindo do poema "A ponte do riacho", o grupo pesquisou e descobriu que o pintor que representava em sua obra a ponte era Monet: "Era uma vez um pintor aqui de Porto Alegre. Costumava pintar eternamente a Ponte do Riacho" (QUINTANA, 2006, p.25). E as crianças pintaram com guache uma ponte e escreveram sobre a ponte de Monet:

A ponte Monet 
Acho o riacho bonito

Riacho apareceu num trabalho de Monet

Monet era pintor

Pintor muito famoso

Que faz até dar gosto

Gosto da sua pintura

Que só tinha belezura!

(Criança V)

Leu-se o registro de um diário no poema de Mário Quintana: “Tenho 9 anos. Meu nome é Gravilo. Meu professor só hoje me permitiu uma ida ao Jardim Botânico, por causa da minha redação sobre a fórmula de Einstein" (QUINTANA, 2006, p. 34). No encontro anterior, falamos sobre a obra de Monet. Surgiu, assim, o interesse do grupo em conhecer a biografia do pintor, que foi pesquisada na Internet. Depois de ler o poema "De um diário íntimo do Fim do Século Trinta" e, em especial, os versos acima citados, apareceu a idéia da autobiografia:

Diário de mentiras

Um dia eu menti

Menti estar doente

Para não ser estudante

Menti estar com dor de dente

E voltei para casa antes do poente

Menti até no colégio ontem

Que uma briga era uma brincadeira. 
(Criança C)

O tema "susto" também foi motivador porque, mesmo o poema falando de um casarão que não era assustador, porém povoado de fantasmas, eles levaram um susto: "Um velho casarão bem-assombrado aquele que habitei ultimamente" (QUINTANA, 2006, p. 24). Depois de verem o desenho do Gasparzinho, que no enredo mostrava fantasmas que não eram camaradas como a personagem principal, mas que tinham a intenção de dar susto, as crianças montaram um móbile com figuras de fantasmas, vampiros, caveiras e etc, e fizeram seus poemas:

O fantasma assustador

Quando o fantasma assusta

Deixa tudo bagunçado

Quando ele não assusta

deixa tudo arrumado.

(Criança V)

A leitura do poema "Se eu fosse um padre": "Se eu fosse um padre eu citaria os poetas.// Rezaria seus versos, os mais belos,/ desses que desde a infância me embalaram/ e quem me dera que alguns fossem meus!// Porque a poesia purifica a alma.../ e um belo poema - ainda que de Deus se aparte -/ um belo poema sempre leva a Deus!” (QUINTANA, 1994, p.52), permitiu que cada um completasse a frase que dá nome ao poema com uma personagem. Depois, cada criança representou aos colegas a personagem através da dramatização. Cada uma fez seu poema pensando na personagem criada:

Se eu fosse...

Se eu fosse um corredor de fórmula um

Eu seria o número um

Um mais veloz 


\author{
Um mais experiente \\ Um campeão \\ É isso que eu desejo ser \\ Para poder festejar \\ Um primeiro lugar
}

(Criança V)

Ao ler "Os poemas": "Os poemas são pássaros que chegam/ não se sabe de onde e pousam/ no livro que lês" (QUINTANA, 1994, p.18), falar do poema foi uma forma de as crianças entenderem o que haviam aprendido até o momento. Foi realizada uma conversa informal, lembrando os poemas preferidos de cada uma. Então, a finalização foi escrever, falando de poema:

\author{
Poema \\ O poema é como um beijo \\ Acontece e eu nem vejo \\ Vem rápido \\ Assim também vai embora
}

(Criança W)

Discutir o real sentido do Natal e falar de esperança foi muito proveitoso como encerramento do trabalho nas oficinas: "Silêncios. Sinos. Apelos. Sinos./ E sinos. Sinos. E sinos. Sinos./ Pregoeiros. Sinos. Risadas. Sinos./ E levada pelos sinos,/ todo ventando de sinos,/ dança a cidade no ar!” (QUINTANA, 2005, p. 39). O grupo, por votação, achou que o Papai Noel é o representante do Natal. Por isso, foi montado um Papai Noel com papel picado. E o motivo da escrita foi o Natal: 
Sinos de Natal

O Natal é alegre

Alegre quando vem

Triste quando vai

Quando o Natal vai embora

Nem ao menos dá tchau.

(Criança C)

Com a leitura de "Poema do fim do ano": "Lá bem no alto do décimo segundo andar do Ano/ mora uma louca chamada Esperança:/ E quando todas as buzinas fonfonam/ quando todos os reco-recos matracam/ quando tudo berra quando tudo grita quando tudo apita/ a louca tapa os ouvidos/ atira-se" (QUINTANA, 2005, p.37), o grupo fez um mural com gravuras de revista, representando esperança:

O primeiro dia do ano

O ano novo é bem novo

Enche tudo de mania

De esperança e fantasia

A esperança é o segredo

De esperar um mundo melhor!

(Criança V)

\section{CONSIDERAÇÕES FINAIS}


Ao final dos quinze encontros com as crianças era possível perceber o entrosamento delas com a poesia, maior facilidade para escrever e melhoras significativas na leitura. A poesia, no grupo de crianças manifestava-se através de uma linguagem centrada no sentimento, na emoção e descompromissada com a concordância, com a verdade, que na poesia é transcendental. Como diz Mário Quintana: “A verdade do mundo poético/ não tem de dar satisfação à verdade/ do mundo real”' (QUINTANA, 1977, p.77). E, assim, seguindo os passos das oficinas, as crianças produziram muitos poemas.

Com o desenvolvimento das atividades, as crianças foram demonstrando mais facilidade para escrever, usando palavras de sentido mais amplo e conseguindo pensar na construção do verso, de modo a explorar recursos poéticos. Aconteceu a descentração da escrita, pois elas já demonstraram capacidade para escrever sobre temas do mundo, para apreciar as coisas e falar sobre elas, não somente sobre a própria realidade, como era no início, mas sobre todas as coisas.

Outro aspecto que revelou resultados positivos no desenvolvimento das crianças foi observado na oralidade. No primeiro encontro, as crianças responderam a uma pergunta, e a mesma foi repetida no último dia, com a intenção de registrar a evolução pessoal de cada um. Os registros finais mostraram respostas mais detalhadas e completas, as frases eram mais organizadas, as crianças mostraram facilidade para falar em poesia. Elas responderam à pergunta: Como se escreve poesia? No começo, responderam com bastante dificuldade: - Rimando as palavras; - Gostando de escrever, porque é divertido; - Pensando para inventar; - Olhando as coisas. No final, elas foram além: Pode-se escrever sobre qualquer coisa; - O mundo é feito de idéias; - Os versos fazem voar o pensamento; - Para escrever tem que começar e saber apreciar as belezas ( frases ditas pelas crianças e registradas pela monitora).

De acordo com LOUREIRO (2005), criar condições para a expressão e discussão de questões importantes para os alunos, levando-os, no contexto da sala de aula, para o âmbito social, facilita o desbloquear desses alunos para a aprendizagem e para o crescimento humano.

O crescimento, de um modo geral, foi também observado pelas professoras de algumas crianças, com as quais foi possível contato. Elas mencionaram alguns fatos importantes de serem resgatados, como registro dos resultados alcançados pelas crianças no crescimento individual, tanto de aprendizagem quanto de socialização. 
A mudança de atitude apareceu no surgimento do hábito da leitura, partindo do aluno o desejo de retirar livro na biblioteca: interesse que ele tem demonstrado em pegar mais livros na biblioteca, ler mais ( transcrição da fala da Professora 2). Quanto à socialização, também apareceu melhoras percebidas pela professora, pois o aluno demonstrou querer fazer os trabalhos de forma mais independente e mais confiante no seu potencial: Mas eu vejo que ele melhorou bastante, a socialização dele também; saiu um bom trabalho, pra ele que é bem dependente, ele precisa que tu esteja ali apoiando ele, e ele se deslanchou sozinho; Eu acho que esse trabalho de poesia também ajudou nessa construção (transcrição da fala da Professora 1).

Necesita-se estimular o contato com os diversos gêneros textuais que a criança encontra na sociedade letrada, como jornais, revistas, embalagens, pois todos são recursos para atos de leitura em sala de aula. "Prover o espaço das crianças com histórias, poemas ou livros informativos é uma condição essencial para favorecer o acesso à língua escrita e para motivar o desejo de aprender a ler". (TEBEROSKY e COLOMER, 2003, p. 145).

\section{REFERÊNCIAS}

BRASIL. Secretaria de Educação do Ensino Fundamental. Parâmetros Curriculares Nacionais: Língua Portuguesa. Ministério da Educação. Secretaria da Educação Fundamental 3.ed. Brasília: A Secretaria, 2001.

LOUREIRO, Stefanie Arca Garrido. Alfabetização: Uma Perspectiva Humanista e Progressista. São Paulo: Autentica, 2005.

MARCONI, Maria de Andrade; LAKATOS, Eva Maria. Metodologia científica. São Paulo: Atlas, 2009.

MENÉRES, Maria Alberta. O poeta faz-se aos 10 anos. Lisboa: Plátano, 1977.

QUINTANA, Mário. Caderno H. Porto Alegre: Globo, 1977.

Sapo amarelo. São Paulo: Global, 2006.

Sapato furado.São Paulo: FTD, 1999.

. Nariz de vidro. São Paulo: Moderna, 2003.

Lili inventa o mundo. São Paulo: Global, 2005.

O batalhão das letras. São Paulo: Globo, 1999.

Pé de pilão. São Paulo: Ática, 1999.

Cadernos Cajuína, V. 5, N. 1, 2020, p. 4-20. 
TEBEROSKY, Ana; COLOMER, Teresa. Aprender a ler e a escrever: uma proposta construtivista. Porto Alegre: Artmed, 2003.

VIEIRA, Elaine \& VOLQUIND, Lea. Oficinas de Ensino: O quê? Por Quê? Como? Porto Alegre: PUCRS, 1996. 